\section{Step back to see how science and humanity fit in the big picture}

Sir - Although your Millennium Essays focus on events in the past 1,000 years, it is easy to lose perspective when analysing time-windows much greater than our lifespan. Our brains are not adapted to think in vast time-frames. So it may be helpful to take a bird's-eye view of our past millennium by using a series of time-windows - each one-hundredth the size of the previous one — to extend the analysis deeper in time.

In the largest time-window imaginable, comprising tens of millions of millennia, the past millennium doesn't show up. This window places the formation of Earth and the emergence of life in perspective: if the event creating our present Universe (the Big Bang) occurred around 15.5 million millennia ago, the development of life on Earth represents about $25 \%$ of the history of our Universe.

One per cent of this large window produces a second time-window covering the past 200,000 millennia, in which evolved extant animals and plants, primates and, finally, hominids.

In the third window, spanning 2,000 millennia, human invention starts to become apparent. Stone tools were used during the first half and fire was domesticated around the halfway point. These preceded the formation of the oldest-known fossils of Homo erectus, showing that creativity, technology development and invention were possessed by at least some of the australopithecine and other hominids long before H. sapiens appeared. Human creativity developed slowly, leaving the earliest paintings as evidence at the end of this window. This time-window saw the extinction of many other creatures (including all hominids except H. sapiens) — some caused by the sophisticated traps and projectiles made by H. sapiens.

The fourth time-window, using a 20millennia lens, shows that both extinctions and human creativity continued to accelerate. Humans were weaving clothes at the beginning of this period, before the last ice age, by the end of which plants and animals were domesticated. This led to the development of agriculture about 10 millennia ago. The development of ceramics, the wheel, iron, bronze, steel and written documents followed at ever-shorter intervals. The use of script gives us a direct view on the thought processes of Homer, Lao-Tse, Buddha, Aristotle, Christ, Ptolemy, Muhammad and many others. These scripts show that human emotion did not differ significantly then from that experienced today.

Five per cent of this 20-millennia timewindow focuses on the past millennium.
The main feature of this millennium seems to have been the emergence of the scientific method. Science, defined as the method that subordinates theory to experimental results, was pioneered by Galileo and has been widely accepted as a superior form of thought only during the past two centuries. An interesting aspect is the shift of creative power from China to the West as the nationalistic and xenophobic policies of the Ming dynasty, started by Chu Yuan-chang in 1368, hindered commerce and the expansion of creativity in China. I detect a pause in the growth of creativity in the Christian world, spanning the first millennium AD (after Ptolemy and the Roman Emperor Julianus) to the Renaissance, overlapping with bursts of creativity in the Islamic world.

The past millennium shows no sign that the exponential expansion of human mental capabilities has stabilized. Evolution of other animal species, however, suggests that exponential evolutionary development of behavioural or morphological traits eventually stops. Even human creativity may start to do so in the third millennium AD.

Klaus Jaffe

Department of Biology, Universidad Simón Bolivar, Caracas 1080, Venezuela

\section{Patent dispute hangs over kringle 5}

Sir - In June you published a News brief relating to a suit brought by Abbott Laboratories against Children's Hospital in Boston and against me and two of my younger associates ${ }^{1}$. The suit asserted rights to a patent assigned to Children's Hospital on an endothelial and angiogenesis inhibitor called kringle 5 which was discovered in the hospital's laboratories.

Abbott's claim is limited to one small aspect of Children's Hospital work, not involving any work on angiogenesis or the discovery of the angiogenesis inhibitors angiostatin, endostatin, or others.

If an academic institution wants to see its laboratory discoveries translated to the bedside, it must seek patents. Patent disputes, unfortunately, are not unusual. What is unusual here is that Abbott Laboratories, in a deliberate attempt to claim for itself a discovery that it neither made nor owns, has attacked the integrity of scientists at Children's Hospital and has publicized its false allegations worldwide.

I have no personal financial interest in this matter. My only objective is to see that medical advances are brought to clinical application so that patients can benefit. It will be reprehensible if Abbott's actions disrupt or delay this.

Abbott's claims against Children's Hospital, me and my associates are false and malicious. The truth of the matter is as follows. First, Abbott based many of its claims in court on an alleged confidentiality disclosure agreement and attached the agreement as a key part of its court filings. The alleged agreement was originally sent to Children's Hospital in June 1995, but it was never agreed to by the hospital nor returned to Abbott. The hospital's Office of Technology rejected the sweeping agreement. A technology office official wrote many comments on the document and in July 1995 told Abbott and its employee Donald Davidson that the agreement was unacceptable. He forwarded to Abbott an alternative agreement, but Abbott never signed it.

Second, five months later I received a letter from Abbott clearly acknowledging the lack of any agreement with Children's Hospital and proposing that, in the absence of a legal agreement, we enter into a "gentlemen's agreement" whereby Abbott would provide plasminogen fragments in exchange for my laboratory continuing to provide Abbott with expertise and materials. Abbott also proposed that Davidson and another Abbott employee visit my laboratory to learn more. I informed Abbott that we did not wish their employees to visit, but that we would be happy to share our expertise and cell lines with Abbott, which we did.

Third, Davidson was working on the thrombolytic (clot lysing) properties of plasminogen and had no idea that any fragment of plasminogen had anti-endothelial or anti-angiogenic activity until after my laboratory published the discovery of angiostatin in Cell ${ }^{2}$ in October 1994, six months after Yihai Cao in my laboratory first requested plasminogen fragments from Davidson and other scientists, including Miguel Llinas of Carnegie Mellon University and Stephen McCance of American Biogenetic Sciences and Notre Dame.

Fourth, the anti-endothelial and antiangiogenic properties of various kringle fragments of plasminogen were discovered by Cao, Michael O'Reilly and me. Cao and O'Reilly were postdoctoral fellows in my laboratory at Children's Hospital.

Fifth, Cao published two papers on his results $^{3,4}$. He graciously included Davidson, McCance and Llinas as co-authors because they supplied plasminogen fragments or advice on preparing those fragments.

Last, on 18 July 2000, Children's Hospital filed a detailed answer and counterclaims, and on 14 August, Abbott filed a pleading in court admitting that it had doctored the alleged agreement it had attached to its complaint.

Judah Folkman

Children's Hospital, 300 Longwood Ave, Boston, Massachusetts 02115, USA

1. Nature 405, 608 (2000).

2. O'Reilly, M. S. et al. Cell 79, 315-328 (1994).

3. Cao, Y. et al. J. Biol. Chem. 271, 29461-29467 (1996).

4. Cao, Y. et al. J. Biol. Chem. 272, 22924-22928 (1997). 